\title{
X-ray photoelectron spectroscopic study of silicon surface passivation in alcoholic iodine and bromine solutions
}

\author{
Neha Batra, Vandana, Praveen Kumar, S. K. Srivastava, and P. K. Singh ${ }^{\text {a) }}$ \\ CSIR-National Physical Laboratory (Network of Institutes for Solar Energy), \\ New Delhi, 110012 India
}

(Received 11 September 2012; accepted 8 January 2014; published online 27 January 2014)

\begin{abstract}
We report an X-ray photoelectron spectroscopic (XPS) study of silicon surfaces passivation using alcoholic solutions of iodine and bromine where different behavior with two systems is observed. The minority carrier lifetime determined by microwave photoconductive decay method showed better surface passivation for iodine-alcoholic system with HF preconditioning step. The iodine-ethanol (I-E) passivated samples show strong Si-I bonding (two times) in Si core level spectra for the samples without oxide (25.5\%) compared with oxide (10.2\%) counterpart. However, bromine-ethanol (B-E) passivated samples show higher $\mathrm{Si}-\mathrm{Br}$ bonding strength in the samples with oxide (24.7\%) compared to without oxide specimens $(12.0 \%)$. This may be the reason of difference in passivation behavior of I-E and $\mathrm{B}-\mathrm{E}$ systems. Higher $\mathrm{O}-\mathrm{Br}$ bonding in $\mathrm{O}$ core level spectra of $\mathrm{B}-\mathrm{E}$ passivated samples with oxide (35.8\%), compared to without oxide (20.7\%), results in comparable lifetime values in both with and without preconditioning. To understand the effect of solvent on the passivation, experiments are performed using iodine-methanol (I-M) and bromine-methanol (B-M) solutions and XPS analysis shows similar $\mathrm{Si}-\mathrm{I}, \mathrm{Si}-\mathrm{Br}$, and $\mathrm{O}-\mathrm{Br}$ bonding trends. (C) 2014 AIP Publishing LLC. [http://dx.doi.org/10.1063/1.4863087]
\end{abstract}

\section{INTRODUCTION}

The bulk minority carrier lifetime is an important parameter in semiconductors which limits the performance of the minority carrier based devices like solar cell. ${ }^{1}$ It is also used for monitoring the material quality and at times as a measure of process cleanliness in foundries. Therefore, information of this parameter is of utmost importance. The measured minority carrier lifetime $\left(\tau_{\text {eff }}\right)$ value ${ }^{2}$ has contributions from the bulk $\left(\tau_{\mathrm{b}}\right)$ and the recombination lifetimes associated with the wafer surfaces $\left(\tau_{\mathrm{s}}\right)$. These two parameters are related to measured effective lifetime value as

$$
\frac{1}{\tau_{e f f}}=\frac{1}{\tau_{b}}+\frac{1}{\tau_{s}}
$$

where $\tau_{\mathrm{s}}$ is equal to $\left(\mathrm{D}_{\mathrm{p}} \beta^{2}\right)^{-1}$ and is related to surface recombination velocity (S) through the relation $\beta \tan (\beta \mathrm{d} / 2)=\mathrm{S} / \mathrm{D}_{\mathrm{p}}$. In the case of high lifetime material, measured lifetime is primarily a measure of surface recombination.

To estimate true value of $\tau_{\mathrm{b}}$, the contribution of the two surfaces should be minimized that can be realized by surface passivation. Chemical passivation and field effect passivation ${ }^{3-7}$ are commonly used processes for surface passivation. In the former, the interface defect density is reduced by passivation of dangling bonds by attachment of atomic hydrogen present in thin dielectric layers of a-Si:H, $\mathrm{Si}_{\mathrm{x}} \mathrm{N}_{\mathrm{y}}: \mathrm{H}$, etc., or by chemisorption of $\mathrm{Br}$ or I atoms with silicon surface. In the case of field effect passivation, electron and hole concentration at interface is

\footnotetext{
a) Author to whom correspondence should be addressed. Electronic mail: pksingh@nplindia.org. Tel.: +91 1145721078. Fax: +91 1145609310 . 
altered by electrostatic shielding by fixed interface charges present in $\mathrm{Al}_{\mathrm{x}} \mathrm{O}_{\mathrm{y}}, \mathrm{a}-\mathrm{Si}: \mathrm{H}, \mathrm{SiO}_{\mathrm{x}}$, $\mathrm{Si}_{\mathrm{x}} \mathrm{N}_{\mathrm{y}}$, and a-SiC:H films. However, the formation of these layers requires expensive process equipment and infrastructure and is, generally made at high temperatures that may result in degradation of carrier lifetime. ${ }^{8}$ In many cases, both the processes (chemical and field effect passivation) work in tandem.

Chemical passivation is an easy, fast, and effective route to reduce surface recombination losses which can be realized at room temperature. The advantage of chemical passivation is that it can easily be adopted at any stage of device fabrication to determine the minority carrier lifetime during process development, i.e., to act as a check of process induced effect on the material's lifetime. The passivation of silicon surfaces is carried out by using alcoholic solution of iodine, bromine and quinhydrone, etc. ${ }^{9-12}$ besides concentrated HF. However, the mechanism responsible for surface passivation is still not clear and a matter of debate. In the present study, an attempt is made to understand the mechanism of surface passivation under different surface conditions. For this, X-ray photoelectron spectroscopy (XPS) is used due to its strength to find out the oxidation state without involvement of complex precursor chemistry and precise surface monitoring (being an ultra high vacuum technique). The minority carrier lifetime and XPS measurements are performed before and after surface passivation by using alcoholic solutions of iodine and bromine (in two different solvents, i.e., ethanol and methanol) under two different surface conditions (i.e., with and without oxide on the two surfaces). The data is analyzed to understand mechanism involved in the process of passivation. The chemical used in the present study are environmentally benign except bromine and HF which are required in small quantities. The study reported in this paper is important for silicon photovoltaic as it provides information about the minority carrier lifetime, a vital parameter for device performance. The advantage of this process is that it is non-destructive in nature.

\section{EXPERIMENTAL}

In the present study, $\langle 100\rangle$ p-type (boron-doped), float-zone (FZ) single-crystalline silicon wafers of $5 \pm 0.5 \Omega$-cm resistivity and minority carrier lifetime of more than $500 \mu$ s are chosen. The wafers are chemical-mechanically polished (both sides) with $650 \pm 10 \mu \mathrm{m}$ thickness and $150 \mathrm{~mm}$ diameter. The samples of $30 \mathrm{~mm} \times 30 \mathrm{~mm}$ are diced from the single large wafer using a laser scriber and, therefore, all the eight samples $\left(\mathrm{S}_{1}-\mathrm{S}_{8}\right)$ have identical surfaces, electrical and optical properties. The samples are cleaned in $\mathrm{H}_{2} \mathrm{O}_{2}: \mathrm{H}_{2} \mathrm{SO}_{4}$ (1:4 by volume) solution for $10 \mathrm{~min}$ and rinsed thoroughly in $18.2 \mathrm{M} \Omega$ de-ionised (DI) water. After this step, generally a thin layer of oxide is formed on the two surfaces of samples. Two types of samples, one with oxide and the other without oxide (obtained after dipping in 5\% HF for 1 min to remove oxide followed by DI water rinse), are made for passivation studies. The term with oxide and without oxide is invariably referred as pre-conditioning steps or surfaces in the subsequent text. The sample's identification is as given in Table I.

The measurements are carried out with $0.08 \mathrm{M}$ iodine and $0.06 \mathrm{M}$ bromine solutions either in methanol or ethanol. These concentrations are chosen because the maximum lifetime values are obtained at these concentrations in bromine and iodine systems in our earlier studies ${ }^{13}$ (without and with oxide samples). The samples are treated in the alcoholic iodine or bromine solutions for $5 \mathrm{~min}$ and remained there during lifetime measurement. During measurements, uniformly distributed thin layer with minimal amount of solution over the sample is ensured. The complete details of surface passivation experiments can be seen in Ref. 13. After removal from the solution, the samples are quickly transferred to XPS system to minimize effect of ambient, if any. There are reports of unwanted oxidation at surface and absorption of adventitious impurities from ambient. ${ }^{11}$ XPS measurements are carried out using PerkinElmer ultrahigh vacuum system (Physical Electronics; Model: PHI-1257) working at a base pressure of $5 \times 10^{-10}$ Torr, where spectra are recorded using $\mathrm{Mg}-\mathrm{K}_{\alpha}$ as an $\mathrm{X}$-ray source.

The minority carrier lifetime measurements are performed with the help of a spatially resolved microwave photo-conductive decay system ( $\mu$-PCD, Model: WT2000 from M/s Semilab Zrt, Hungary) with a $904 \mathrm{~nm}$ pulsed laser (penetration depth in silicon $\sim 30 \mu \mathrm{m}$ ) for 
TABLE I. Sample identification along with surface conditions.

\begin{tabular}{lcc}
\hline \hline Sample & Solution used for surface passivation & Surface condition remark \\
\hline $\mathrm{S}_{1}$ & Iodine-ethanol (I-E) & with HF (without oxide) \\
$\mathrm{S}_{2}$ & Iodine-ethanol (I-E) & without HF (with oxide) \\
$\mathrm{S}_{3}$ & Bromine-ethanol (B-E) & with HF (without oxide) \\
$\mathrm{S}_{4}$ & Bromine-ethanol (B-E) & without HF (with oxide) \\
$\mathrm{S}_{5}$ & Iodine-methanol (I-M) & with HF (without oxide) \\
$\mathrm{S}_{6}$ & Iodine-methanol (I-M) & without HF (with oxide) \\
$\mathrm{S}_{7}$ & Bromine-methanol (B-M) & with HF (without oxide) \\
$\mathrm{S}_{8}$ & Bromine-methanol (B-M) & without HF (with oxide) \\
\hline \hline
\end{tabular}

optical excitation with a microwave source operating at $10 \mathrm{GHz}$ for signal detection (where decay of excess carrier concentration is monitored by the microwave reflectance). The system operates at low injection levels (i.e., excess carrier density, $\Delta \mathrm{n} \sim 1.2 \times 10^{13} \mathrm{~cm}^{-3}$ ). Another lifetime tester (Model: WT120; from M/s Sinton Inc, USA) is also used in this study, where the injection levels can be varied in a wide range $\left(10^{13}>\Delta \mathrm{n}>10^{16} \mathrm{~cm}^{-3}\right)$. In this tool, excess carriers are generated by a flash and the sheet conductivity is measured by RF coil inductively coupled to sample. The flash intensity and sheet conductivity are converted into generation rate of electron-hole $(\mathrm{e}-\mathrm{h})$ pairs and average excess carrier density, respectively using mobility model. The system operates in (i) quasi steady state photoconductance, QSSC (ii) transient photoconductance (TPC) decay modes. In the QSSC, decay constant of the flash should be at least 10 times slower than the carrier lifetime so that excess carrier's population attains steady state and hence, the lifetime is calculated using steady state condition. In the transient mode, fast pulse of light which peaks and decays back in a time frame of 10-20 $\mu$ s is used and the photoconductance decay is measured to determine effective lifetime. This is suitable for high lifetime materials. We have used both modes for measurements in the present study.

\section{RESULTS AND DISCUSSIONS}

It is known that $\mathrm{Si}(100)$ surface has two dangling bonds per surface (and has higher oxide growth rate) as compared to one on $\mathrm{Si}(111)$ surface. The silicon surface may be either hydrogen $(\mathrm{H}-)$ or fluorine (F-) terminated after $\mathrm{HF}$ treatment. The former takes place after HF etching and the later arises during oxide removal by HF. However, F-terminated surface transforms into $\mathrm{H}$-terminated surface wherein $\mathrm{F}$ atom destabilizes the silicon back surface bonds resulting in $\mathrm{H}$ attachment to the underlying silicon. On the other hand, in the case of halogens like bromine and iodine get chemisorbed on silicon surface resulting in corresponding species terminated surface via covalent bonding.

As mentioned in Table I, four samples: each are processed in alcoholic solutions of iodine $\left(\mathrm{S}_{1}, \mathrm{~S}_{2}, \mathrm{~S}_{5}, \mathrm{~S}_{6}\right)$, and bromine $\left(\mathrm{S}_{3}, \mathrm{~S}_{4}, \mathrm{~S}_{7}, \mathrm{~S}_{8}\right)$ for surface passivation, where two different solvents: ethanol and methanol, are used. The samples exhibit minority carrier lifetime of $11 \pm 0.5 \mu$ s after piranha cleaning (referred as with oxide preconditioned stage) which increased to $42 \pm 2 \mu$ s after HF dip (referred as without oxide preconditioned stage). The $\tau_{\text {eff }}$ values in all eight samples are measured using $\mu \mathrm{PCD}$ at $\Delta \mathrm{n} \sim 1.2 \times 10^{13} \mathrm{~cm}^{-3}$ and the values are listed in Table II. It is to be remarked here that $\tau_{\text {eff }}$ values measured by Sinton's lifetime tester WT120 is within $\pm 10 \%$ of the values obtained by $\mu \mathrm{PCD}$ provided injection levels are matched. Further, the trend in the two values after chemical treatment is also similar. The improvement in $\tau_{\text {eff }}$ values is found after surface passivation using iodine and bromine systems; however, the degree of passivation varies with the surface condition.

In the case of iodine, higher values are obtained in the samples without oxide layer as compared to samples with oxide whereas for the two surface conditions in bromine system, though $\tau_{\text {eff }}$ increased but only marginally. Figure 1 depicts typical effective minority carrier lifetime values obtained at $0.08 \mathrm{M}$ and $0.06 \mathrm{M}$ concentrations of iodine-ethanol and bromine-ethanol 
TABLE II. The measured minority carrier lifetime using $\mu \mathrm{PCD}$ along with calculated values of surface recombination velocity and defect density for iodine and bromine surface passivation system (with and without oxide layer).

\begin{tabular}{|c|c|c|c|c|c|}
\hline \multirow[b]{2}{*}{ Surface conditioning } & \multirow[b]{2}{*}{ Parameter } & \multicolumn{2}{|c|}{ Iodine } & \multicolumn{2}{|c|}{ Bromine } \\
\hline & & Ethanol & Methanol & Ethanol & Methanol \\
\hline \multirow[t]{3}{*}{ With oxide (without HF dip) } & $\tau_{\mathrm{eff}}(\mu \mathrm{s})$ & $96 \pm 5$ & $70 \pm 4$ & $111 \pm 6$ & $120 \pm 6$ \\
\hline & $\mathrm{S}(\mathrm{cm} / \mathrm{s})$ & 338 & 464 & 293 & 270 \\
\hline & $\mathrm{N}_{\mathrm{s}}\left(\times 10^{10}, \mathrm{~cm}^{-2}\right)$ & 57.8 & 79.3 & 50.1 & 46.2 \\
\hline \multirow[t]{3}{*}{ Without oxide (with HF dip) } & $\tau_{\mathrm{eff}}(\mu \mathrm{s})$ & $169 \pm 8$ & $167 \pm 8$ & $115 \pm 6$ & $143 \pm 7$ \\
\hline & $\mathrm{S}(\mathrm{cm} / \mathrm{s})$ & 192 & 194 & 282 & 227 \\
\hline & $\mathrm{N}_{\mathrm{s}}\left(\times 10^{10}, \mathrm{~cm}^{-2}\right)$ & 32.8 & 33.2 & 48.2 & 38.8 \\
\hline
\end{tabular}

solution, respectively, for two different surface pre-conditioned samples (i.e., with and without oxide). In the case of I-E, measured $\tau_{\text {eff }}$ in the sample without oxide is about two times that of the sample with oxide. A similar trend is observed at other iodine concentrations also. On the other hand, a different behavior is observed with B-E solution as compared to the I-E system in the two pre-conditioned surfaces. In this case, the two values are not much different at low injection levels.

In Fig. 2, the effective lifetime is shown in the same p-type wafer passivated by B-E system in order to see injection level dependence of $\tau_{\text {eff. The measurement is carried using WT120 life- }}$ time tester in the $\Delta \mathrm{n}$ range of $10^{13}-10^{15} \mathrm{~cm}^{-3}$. The maximum values of $\tau_{\text {eff }}$ are 146 and $106 \mu \mathrm{s}$ without and with oxide samples, respectively (obtained in the vicinity of $3 \times 10^{14} \mathrm{~cm}^{-3}$ ), and thereafter its value decreases. This behaviour of lifetime versus injection level is similar to the effective lifetime measured by Kerr and Cuevas ${ }^{8}$ for $\mathrm{SiN}$ and oxide passivation and by Chhabra et al. ${ }^{14}$ in chemical passivation using quinhydrone-methanol or iodine-methanol systems at varying injection levels. Generally, the minority carrier lifetime in passivated $p$-type silicon is dominated by Auger recombination in the bulk of the $c$-Si wafer and shows a maximum at a certain injection level ${ }^{15}$ however, its value decreases for both at lower and higher injection levels. These measured minority carrier lifetime values (measured by WT120) are close to the values measured by $\mu \mathrm{PCD}$.

The density of surface recombination centers, $\mathrm{N}_{\mathrm{s}}\left(=\mathrm{S} \sigma^{-1} \mathrm{v}_{\mathrm{th}}{ }^{-1}\right)$ can be estimated ${ }^{12}$ from the calculated values of surface recombination velocity (S). Here, $\sigma\left(=5 \times 10^{-17} \mathrm{~cm}^{2}\right)$ is the hole recombination cross-section and $\mathrm{v}_{\mathrm{th}}\left(=\sqrt{ }(3 \mathrm{kT}) / \mathrm{m}^{*}\right)$ is the carrier thermal velocity and its value is $1.17 \times 10^{7} \mathrm{~cm} / \mathrm{s}$. The symbols $\mathrm{k}, \mathrm{T}$, and $\mathrm{m}^{*}$ represent Boltzmann constant,

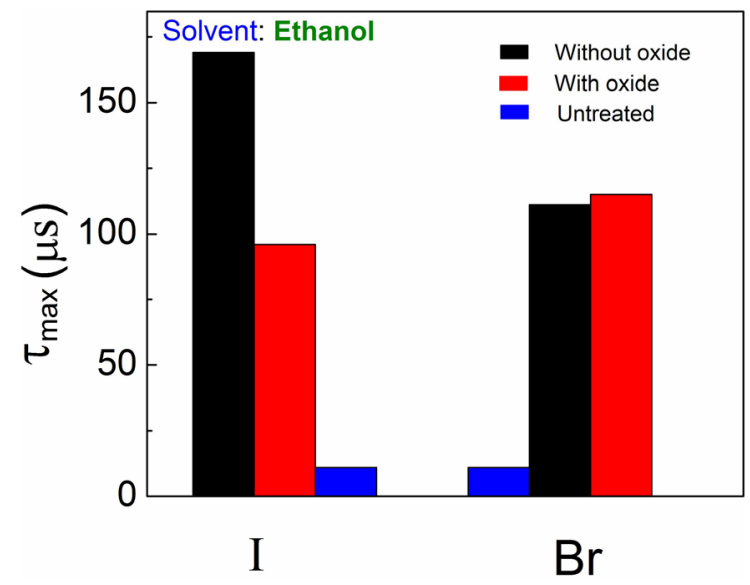

FIG. 1. Bar chart showing effective (measured) minority carrier lifetime $\left(\tau_{\max }\right)$ for the samples passivated by ethanolic solutions of iodine and bromine without oxide (black) and with oxide (red). The blue bar gives measured lifetime in unpassivated sample. 


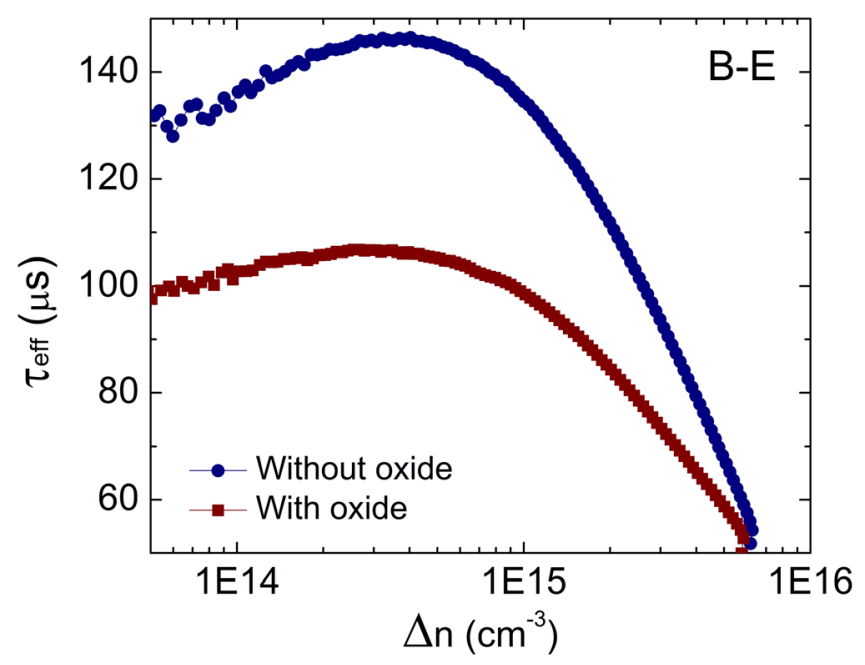

FIG. 2. Measured effective lifetime as a function of the excess carrier density for low resistivity p-type float zone c-Si substrate passivated by bromine-ethanol solution.

temperature, and carrier's effective mass respectively. From the ratio of $\mathrm{N}_{\mathrm{s}}$ and the $\mathrm{Si}(100)$ surface bond density, $\mathrm{N}_{\mathrm{dd}}\left(=1.3 \times 10^{15} \mathrm{~cm}^{-2}\right)$, the degree or effectiveness of surface passivation can be estimated. For example, in case of bromine passivated surface, for $\mathrm{S}=50 \times 10^{10}$ $\mathrm{cm} / \mathrm{s}$, the ratio is equivalent to $\sim 25 \mathrm{ppm}$ of $\mathrm{N}_{\mathrm{dd}}$, i.e., these numbers of centers remain available for recombination. The estimated $\mathrm{N}_{\mathrm{s}}$ values vary from $33 \times 10^{10}$ to $80 \times 10^{10} \mathrm{~cm}^{-2}$ corresponding to the obtained $\mathrm{S}$ values (listed in Table II). Therefore, in the present case, the surfaces are not fully passivated, which may be due to (i) the presence of dissolved oxygen in the solution and/or (ii) partial coverage of iodine or bromine layer. Hence, complete passivation could be expected with a full monolayer coverage. M'saad et al. ${ }^{12}$ have observed higher lifetime in iodine or bromine systems when dissolved oxygen is displaced by nitrogen. The values of $\mathrm{S}$ and $\mathrm{N}_{\mathrm{s}}$ for all the samples are also listed in Table II.

As mentioned earlier, XPS being a surface sensitive technique with a probing depth of $10-20 \mathrm{~nm}$ is used to get qualitative as well as quantitative information of the surface. Few mono-layers of iodine/bromine, (adequate for passivation), are covering the silicon surface during the measurement. Therefore, it is presumed that signatures of $\mathrm{Si}$ and $\mathrm{O}$ as well as $\mathrm{I}$ and $\mathrm{Br}$ could be seen in the XPS data. In this work, we present the XPS core level analysis of $\mathrm{Si}(2 \mathrm{p})$, $\mathrm{O}(1 \mathrm{~s}), \mathrm{I}(3 \mathrm{~d})$, and $\operatorname{Br}(3 \mathrm{~d})$ for the samples $\mathrm{S}_{1}$ to $\mathrm{S}_{8}$. All core level spectra are deconvoluted into their Gaussian components to extract the quantitative bonding information. The intensity of I and $\mathrm{Br}$ core level peaks is low as compared to $\mathrm{Si}$, because of low atomic sensitivity factor. It does not mean that the corresponding element is found in lower concentrations at the surface of the sample. ${ }^{16}$

For the sake of comparison of two surface conditions, i.e., with and without oxide layer, XPS data for both are combined in one figure for one particular system (e.g., (a) I-E, (b) B-E, (c) I-M and (d) B-M). For example $\mathrm{S}_{1}-\mathrm{S}_{2}, \mathrm{~S}_{3}-\mathrm{S}_{4}, \mathrm{~S}_{5}-\mathrm{S}_{6}$, and $\mathrm{S}_{7}-\mathrm{S}_{8}$ are shown in a, b, c, and d of Figs. 3-5, respectively. In all pairs, the upper and lower curves correspond to the samples without $\left(\mathrm{S}_{1}, \mathrm{~S}_{3}, \mathrm{~S}_{5}\right.$, and $\left.\mathrm{S}_{7}\right)$ and with oxide layer $\left(\mathrm{S}_{2}, \mathrm{~S}_{4}, \mathrm{~S}_{6}\right.$, and $\left.\mathrm{S}_{8}\right)$. The $\mathrm{Si}(2 \mathrm{p})$ core level is deconvoluted into three main constituents, namely, $\mathrm{Si}-\mathrm{Si}$ (at $99.9 \mathrm{eV}), \mathrm{Si}-\mathrm{X}(\mathrm{X}=\mathrm{I}$ or $\mathrm{Br}$ at $\sim 100.8 \mathrm{eV}$ ), and $\mathrm{Si}-\mathrm{O}$ (at $103.9 \mathrm{eV}$ ) and are shown in Fig. $3 .{ }^{17,18}$ Any oxidation results in the appearance of additional intensity at higher binding energies. The $\mathrm{Si}(2 \mathrm{p})$ peak of a partially oxidized silicon surface corresponding to $\mathrm{SiO}_{2}$ appears in passivated silicon. The $\mathrm{O}(1 \mathrm{~s})$ core level spectra for all samples is deconvoluted into different Gaussian components: O-Si (at $530.4 \mathrm{eV}$ ), $\mathrm{O}-\mathrm{O}$ (at $531.6 \mathrm{eV})$, and $\mathrm{O}-\mathrm{X}(\mathrm{X}=\mathrm{I} \text { or } \mathrm{Br} \text { at } \sim 533.3 \mathrm{eV})^{19}$ and same is presented in Fig. 4. $\mathrm{Si}(2 \mathrm{p})$ and $\mathrm{O}(1 \mathrm{~s})$ convolution data (area under the curve) is compiled in Table III.

Figure 3 shows the deconvolution of $\mathrm{Si}(2 \mathrm{p})$ core level spectra for all the samples. A comparison of Fig. 3(a) clearly manifests the increase in $\mathrm{Si}-\mathrm{I}$ related contribution and decrease in 
a)

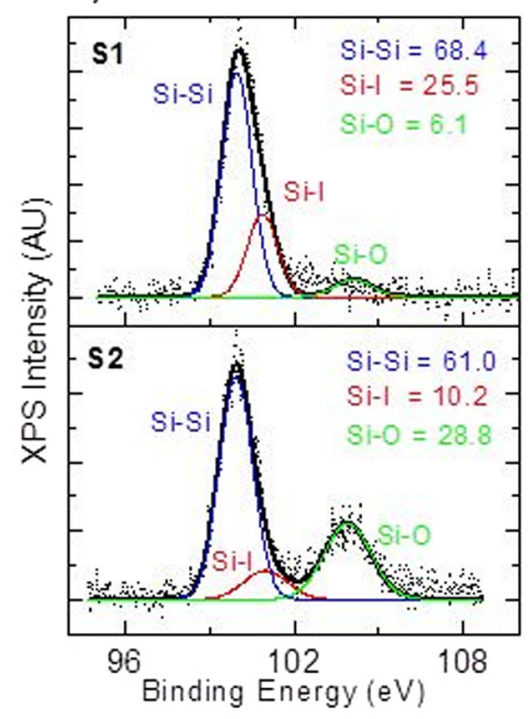

c)

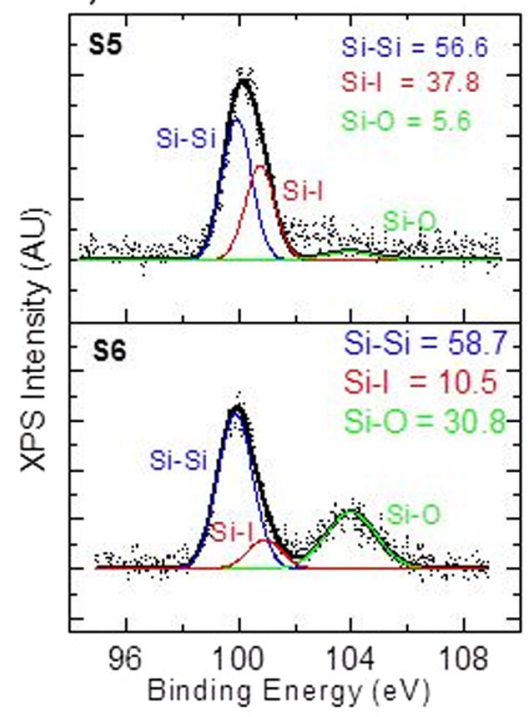

b)

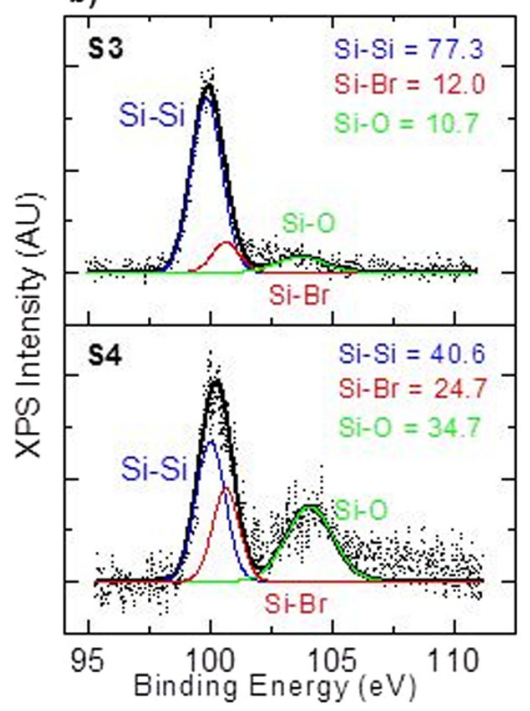

d)

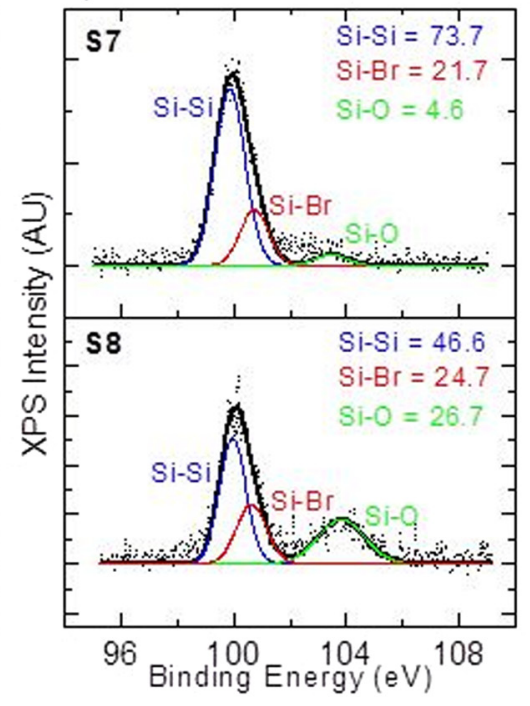

FIG. 3. Deconvoluted $\mathrm{Si}(2 \mathrm{p})$ core level spectra with their $\%$ components where $\mathrm{S}_{1}, \mathrm{~S}_{3}, \mathrm{~S}_{5}$, and $\mathrm{S}_{7}$ correspond to oxide stripped (after HF dip) samples using iodine and bromine with ethanol/methanol whereas $S_{2}, S_{4}, S_{6}$, and $S_{8}$ correspond to samples with oxide (without HF treatment) for iodine and bromine solution in ethanol/methanol.

$\mathrm{Si}-\mathrm{O}$ related contribution for $\mathrm{S}_{1}$ as compared to $\mathrm{S}_{2}$. On the other hand, the deconvoluted $\mathrm{Si}(2 \mathrm{p})$ core level spectra for bromine in ethanol (Fig. 3(b)) shows an opposite trend, i.e., a decrease in $\mathrm{Si}-\mathrm{Br}$ contribution for $\mathrm{S}_{3}$ compared to $\mathrm{S}_{4}$. Figures 3(c) and 3(d) present the $\mathrm{Si}(2 \mathrm{p})$ data for the surface passivation by $\mathrm{I}$ and $\mathrm{Br}$ in methanol, respectively, and clearly support the trend as observed with ethanol system. However, the contribution of $\mathrm{Si}-\mathrm{I}$ has been found 1.5 times in I-M passivation $\left(\mathrm{S}_{5}\right)$ as compared to I-E case $\left(\mathrm{S}_{1}\right)$ whereas $\mathrm{Si}-\mathrm{Br}$ contribution has increased in B-M $\left(S_{7}\right)$ case in without oxide as compared to B-E passivation $\left(\mathrm{S}_{3}\right)$. The Si-Br contribution in ethanol and methanol systems is different by a factor of $\sim 2$ in the samples without oxide layer, but remains practically the same in the samples with oxide layer. Further, we have not observed any other difference in trends particularly with the change in solvent. Overall Fig. 3 clearly indicates that iodine gives enhanced surface passivation with surface preconditioning of without oxide layer while bromine offers less impact of surface preconditioning with both the solvent. It can be seen from the figure that a peak corresponding to native $\mathrm{SiO}_{\mathrm{x}}$ (with oxide) or $\mathrm{SiO}_{2}$ 
a)

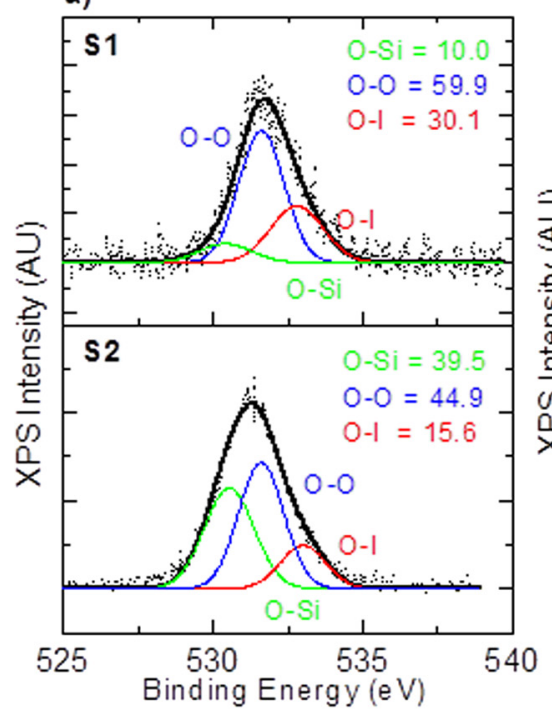

c)

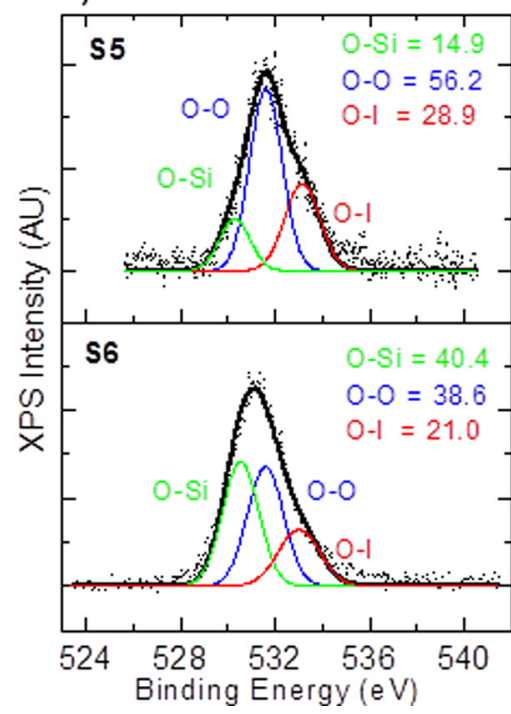

b)

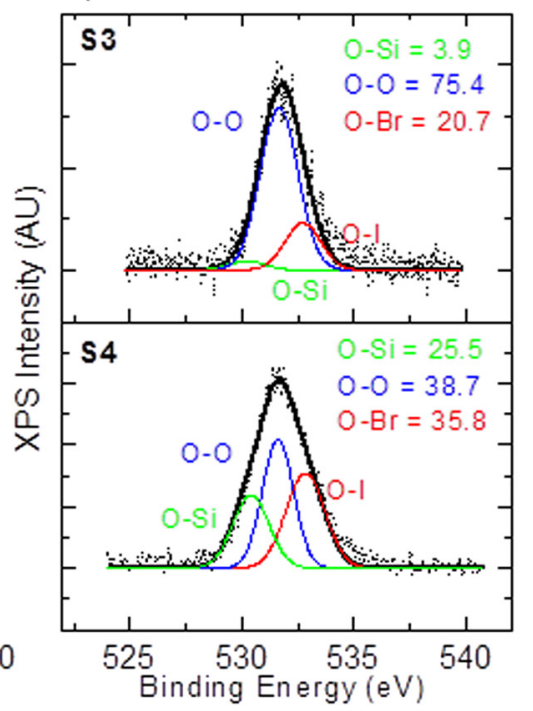

d)

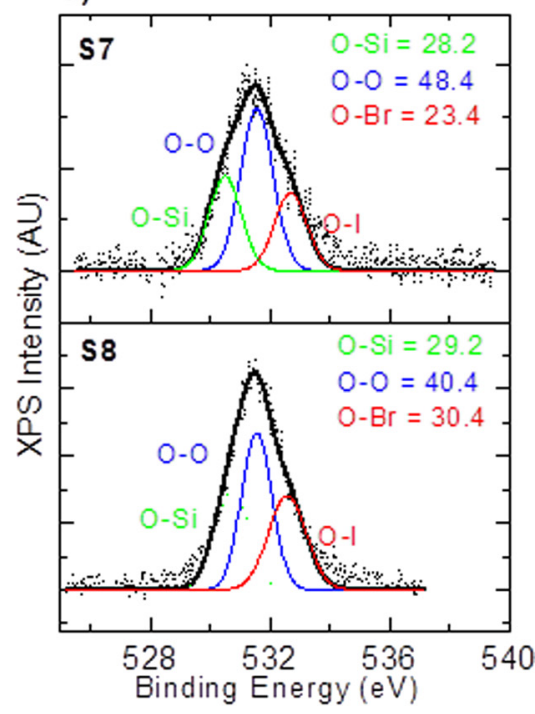

FIG. 4. Deconvoluted $\mathrm{O}(1 \mathrm{~s})$ core level spectra in to their components. $\mathrm{S}_{1}, \mathrm{~S}_{3}, \mathrm{~S}_{5}$, and $\mathrm{S}_{7}$ correspond to the samples stripped of oxide layer and passivation using iodine and bromine with ethanol/methanol whereas $S_{2}, S_{4}, S_{6}$, and $S_{8}$ correspond to samples with oxide layer for iodine and bromine solution in ethanol/methanol.

(without oxide) is observed in the sample, however the intensity is more, as expected, in the oxide case. These results are in agreement with the lifetime data.

The $\mathrm{O}(1 \mathrm{~s})$ spectra give estimate of oxygen content on the sample surface. Figs. 4(a) and 4(b) represent the deconvoluted $\mathrm{O}(1 \mathrm{~s})$ core level spectra for surface passivation in I-E and B-E solutions, respectively, while Figs. 4(c) and 4(d) correspond to the surface passivation in I-M and B-M solutions, respectively. The contribution of $\mathrm{O}-\mathrm{Si}$ in samples $\mathrm{S}_{1}$ and $\mathrm{S}_{3}$ is rather low as compared to $S_{2}$ and $S_{4}$ as expected. This is because the later has the presence of oxide layer over the silicon surface whereas the former is denuded of it. In iodine based systems, the I-O contribution is less in $\mathrm{S}_{2}$ vis-à-vis $\mathrm{S}_{1}$ whereas the $\mathrm{O}-\mathrm{Br}$ contribution is more in $\mathrm{S}_{4}$ with respect to $S_{3}$. It shows better attachment of bromine with oxide layer. A closer look of corresponding $\tau_{\text {eff }}$ values (Table II) shows an agreement with XPS data. Better surface passivation in oxide layered samples is observed in bromine based system whereas high $\tau_{\text {eff }}$ values are observed in oxide stripped samples in iodine based system. The change of solvent from ethanol to methanol 
a)

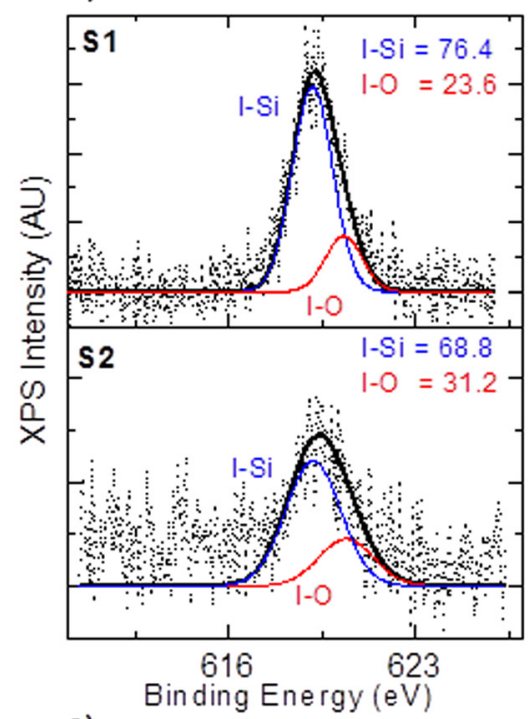

c)

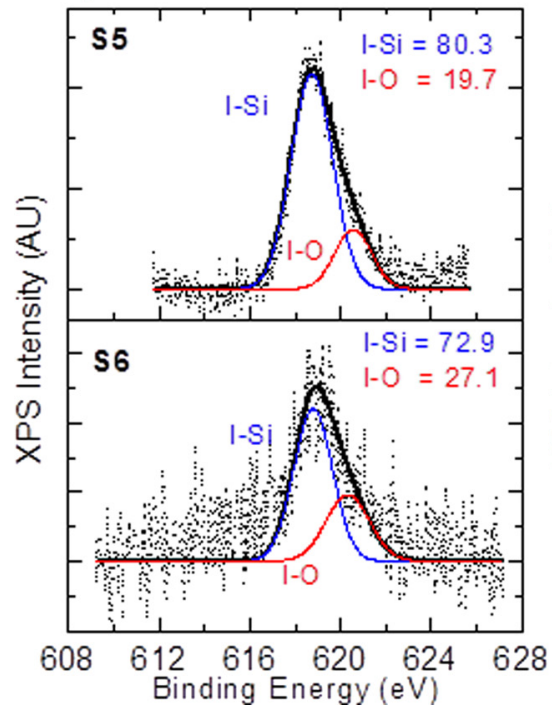

b)

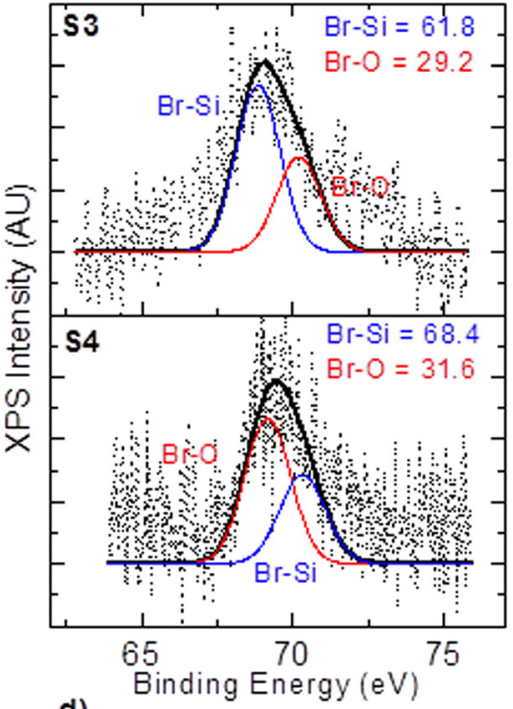

d)

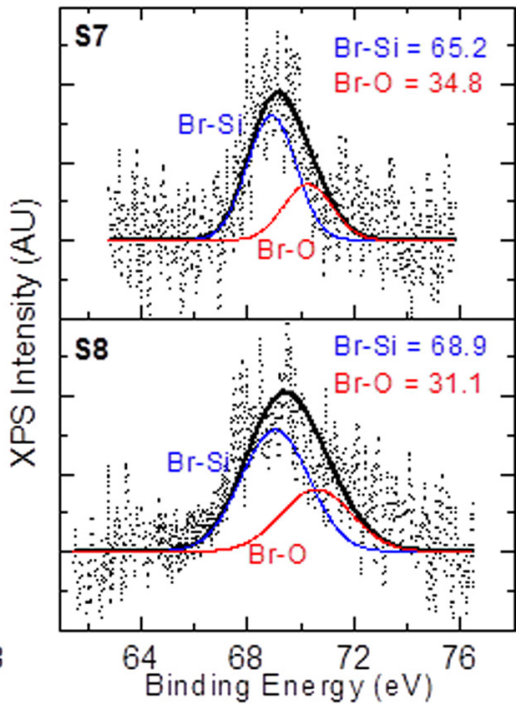

FIG. 5. Deconvoluted I(3d)/Br(3d) core level spectra in to their components. $S_{1}, S_{3}, S_{5}$, and $S_{7}$ correspond to oxide stripped samples using iodine and bromine with ethanol/methanol whereas $S_{2}, S_{4}, S_{6}$, and $S_{8}$ correspond to samples with oxide for iodine and bromine solution in ethanol/methanol.

TABLE III. Quantitative information obtained from $\mathrm{Si}(2 \mathrm{p})$ and $\mathrm{O}(1 \mathrm{~s})$ core level spectra.

\begin{tabular}{|c|c|c|c|c|c|c|c|c|c|c|c|c|}
\hline \multicolumn{7}{|c|}{ Iodine } & \multicolumn{6}{|c|}{ Bromine } \\
\hline & \multicolumn{3}{|c|}{ Ethanol } & \multicolumn{3}{|c|}{ Methanol } & \multicolumn{3}{|c|}{ Ethanol } & \multicolumn{3}{|c|}{ Methanol } \\
\hline $\operatorname{Si}(2 p)$ & $\mathrm{Si}-\mathrm{I}$ & $\mathrm{Si}-\mathrm{Si}$ & $\mathrm{Si}-\mathrm{O}$ & $\mathrm{Si}-\mathrm{I}$ & $\mathrm{Si}-\mathrm{Si}$ & $\mathrm{Si}-\mathrm{O}$ & $\mathrm{Si}-\mathrm{Br}$ & $\mathrm{Si}-\mathrm{Si}$ & $\mathrm{Si}-\mathrm{O}$ & $\mathrm{Si}-\mathrm{Br}$ & $\mathrm{Si}-\mathrm{Si}$ & $\mathrm{Si}-\mathrm{O}$ \\
\hline With oxide & 10.2 & 61.0 & 28.8 & 10.5 & 58.7 & 30.8 & 24.7 & 40.6 & 34.7 & 24.7 & 46.6 & 26.7 \\
\hline Without oxide & 25.5 & 68.4 & 6.1 & 37.8 & 56.6 & 5.6 & 12.0 & 77.3 & 10.7 & 21.7 & 73.7 & 4.6 \\
\hline $\mathrm{O}(1 \mathrm{~s})$ & $\mathrm{O}-\mathrm{Si}$ & $\mathrm{O}-\mathrm{O}$ & $\mathrm{O}-\mathrm{I}$ & $\mathrm{O}-\mathrm{Si}$ & $\mathrm{O}-\mathrm{O}$ & $\mathrm{O}-\mathrm{I}$ & $\mathrm{O}-\mathrm{Si}$ & $\mathrm{O}-\mathrm{O}$ & $\mathrm{O}-\mathrm{Br}$ & $\mathrm{O}-\mathrm{Si}$ & $\mathrm{O}-\mathrm{O}$ & $\mathrm{O}-\mathrm{Br}$ \\
\hline With oxide & 39.5 & 44.9 & 15.6 & 40.4 & 38.6 & 21.0 & 25.5 & 38.7 & 35.8 & 29.2 & 40.4 & 30.4 \\
\hline Without oxide & 10.0 & 59.9 & 30.1 & 14.9 & 56.2 & 28.9 & 3.9 & 75.4 & 20.7 & 28.2 & 48.4 & 23.4 \\
\hline
\end{tabular}


has not affected the passivation for both I and Br (Fig. 4(c): I-M and Fig. 4(d): B-M). Fig. 4 confirms that silicon surface bonding with bromine is dominant in samples with oxide $(\mathrm{O}-\mathrm{Br})$ whereas in iodine system $\mathrm{O}-\mathrm{I}$ bonding is dominant in oxide stripped samples.

The deconvolution of $\mathrm{I}(3 \mathrm{~d})$ and $\mathrm{Br}(3 \mathrm{~d})$ core level spectra ${ }^{14}$ is shown in Fig. 5. It is seen that the I-Si related contribution is higher in samples without oxide, while $\mathrm{Br}-\mathrm{Si}$ related contribution is higher for oxide samples. Similar trend is observed when the solvent is changed from ethanol to methanol. These trends are in line with the $\mathrm{Si}(2 \mathrm{p})$ and $\mathrm{O}(1 \mathrm{~s})$ data as well as in $\tau_{\text {eff }}$ values.

In brief, surface pre-conditioning has greater impact on the quality of surface passivation with iodine based system in the samples stripped of oxide layer, whereas there is only marginal effect in bromine based systems. Further $\tau_{\text {eff }}$ values do not show strong solvent dependence. Bromine passivation is slightly better in oxide stripped samples. These results are supported by XPS data. The advantage of bromine based passivation lies in terms of the stability (aging) due to superior bond strength of $\mathrm{Si}-\mathrm{Br}(=368 \mathrm{~kJ} / \mathrm{mol})$ as compared to $\mathrm{Si}-\mathrm{I}(=293 \mathrm{~kJ} / \mathrm{mol})$.

\section{CONCLUSIONS}

The silicon surfaces passivation using alcoholic solutions of iodine and bromine are investigated using XPS. For silicon surfaces without oxide, iodine provides superior passivation as compared to bromine based systems. On the other hand, almost the same quality of passivation is realized with alcoholic bromine solution in the samples with and without oxide layer. These observations are in agreement with minority carrier lifetime values measured after passivation using the iodine and bromine system. The change in solvent (methanol or ethanol) does not have bearing on the passivation quality. These findings are important for the evaluation of silicon material in terms of minority carrier lifetime.

\section{ACKNOWLEDGMENTS}

The work was carried out under NWP-55 Grant from Council of Scientific and Industrial Research (CSIR), India under TAPSUN initiative. NB also thanks to MNRE for financial support during this work and presently to CSIR in the form of research fellowship.

${ }^{1}$ T. Saga, "Advances in crystalline silicon solar cell technology for industrial mass production," NPG Asia Mater. 2, 96-102 (2010).

${ }^{2}$ A. V. Shah, H. Schade, M. Vanecek, J. Meier, E. Vallat-Sauvain, N. Wyrsch, U. Kroll, C. Droz, and J. Bailat, "Thin-film silicon solar cell technology," Prog. Photovoltaics 12, 113-142 (2004).

${ }^{3}$ D-H. Neuhaus and A. Münzer, "Industrial silicon wafer solar cells," Adv. OptoElectron. 2007, 24521-24535 (2007).

${ }^{4}$ J. Schmidt, M. Kerr, and A. Cuevas, "Surface passivation of silicon solar cells using plasma-enhanced chemical-vapourdeposited SiN films and thin thermal $\mathrm{SiO}_{2}$ /plasma SiN stacks," Semicond. Sci. Technol. 16, 164-170 (2001).

${ }^{5}$ W. Soppe, H. Rieffe, and A. Weeber, "Bulk and surface passivation of silicon solar cells accomplished by silicon nitride deposited on industrial scale by microwave PECVD," Prog. Photovoltaics 13, 551-569 (2005).

${ }^{6}$ S. Kumar, P. K. Singh, and S. R. Dhariwal, "Effect of surface passivation on generation and recombination lifetimes in silicon wafer studied by impedance spectroscopy,” Appl. Phys. Lett. 96, 162109-162111 (2010).

${ }^{7}$ J. Schmidt, A. Merkle, R. Brendel, B. Hoex, M. C. M. van de Sanden, and W. M. M. Kessels, "Surface passivation of high-efficiency silicon solar cells by atomic-layer-deposited $\mathrm{Al}_{2} \mathrm{O}_{3}$," Prog. Photovoltaics 16, 461-466 (2008).

${ }^{8}$ M. J. Kerr and A. Cuevas, "Very low bulk and surface recombination in oxidized silicon wafers," Semicond. Sci. Technol. 17, 35-38 (2002).

${ }^{9}$ A. W. Stephens and M. A. Green, "Effectiveness of 0.08 molar iodine in ethanol solution as means of chemical surface passivation for photoconductance decay measurements," Sol. Energy Mater. Sol. Cells 45, 255-265 (1997).

${ }^{10}$ B. P. Swain, H. Takato, and I. Sakata, "Wet chemical surface passivation of germanium wafers by quinhydrone-methanol treatment for minority carrier lifetime measurements," Appl. Phys. Express 2, 105501-105503 (2009).

${ }^{11}$ B. Chhabra, C. Weiland, R. L. Opila, and C. B. Honsberg, "Surface characterization of quinhydrone-methanol and iodine-methanol passivated silicon substrates using X-ray photoelectron spectroscopy," Phys. Status Solidi A 208, 86-90 (2011).

${ }^{12}$ H. M'saad, J. Michel, J. J. Lappe, and L. C. Kimerling, "Electronic passivation of silicon surfaces by halogens," J. Electron. Mater. 23, 487-491 (1994).

${ }^{13}$ N. Batra, Vandana, S. Kumar, M. Sharma, S. K. Srivastava, P. Sharma, and P. K. Singh, "A comparative study of silicon surface passivation using ethanolic iodine and bromine solutions," Sol. Energy Mater. Sol. Cells 100, 43-47 (2012).

${ }^{14}$ B. Chabbra, S. Bowden, R. L. Opila, and C. B. Honsberg, "High effective minority carrier lifetime on silicon substrates using quinhydrone-methanol passivation," Appl. Phys. Lett. 96, 063502-063505 (2010).

${ }^{15}$ M. J. Kerr and A. Cuevas, "General parameterization of Auger recombination in crystalline silicon," J. Appl. Phys. 91, 2473 (2002). 
${ }^{16}$ C. D. Wagner, W. M. Riggs, L. E. Davis, J. F. Moulder, and G. E. Muilenberg, Handbook of X-ray Photoelectron Spectroscopy (PerkinElmer Corp., 1979).

${ }^{17}$ F. J. Himpsel, F. R. McFeely, A. T. Ibrahimi, J. A. Yarmoff, and G. Hollinger, "Microscopic structure of the $\mathrm{SiO}_{2} / \mathrm{Si}$ interface," Phys. Rev. B 38, 6084-6096 (1988).

${ }^{18}$ K. Sekar, G. Kuri, D. P. Mahapatra, B. N. Dev, J. V. Ramana, S. Kumar, and V. S. Raju, "X-ray photoelectron spectroscopic study of $\mathrm{Si}(111)$ and $\mathrm{Si}(100)$ surfaces with chemically adsorbed bromine," Surf. Sci. 302, 25-36 (1994).

${ }^{19}$ E. J. Nemanick, P. T. Hurley, J. W. Lauren, D. W. Knapp, D. J. Michalak, B. S. Brunschwig, and N. S. Lewis, "Chemical and electrical passivation of single-crystal silicon(100) surfaces through a two-step chlorination/alkylation process," J. Phys. Chem. B 110, 14770-14778 (2006). 